\title{
Article \\ Biomechanical Analysis of Posterior Ligaments of Cervical Spine and Laminoplasty
}

\author{
Norihiro Nishida ${ }^{1}\left(\mathbb{D}\right.$, Muzammil Mumtaz ${ }^{2}$, Sudharshan Tripathi ${ }^{2}$, Amey Kelkar $^{2}$, Takashi Sakai ${ }^{1}$ \\ and Vijay K. Goel ${ }^{2, *}$ \\ 1 Department of Orthopedic Surgery, Yamaguchi University Graduate School of Medicine, \\ 1-1-1 Minami-Kogushi, Ube, Yamaguchi Prefecture 755-8505, Japan; nishida3@yamaguchi-u.ac.jp (N.N.); \\ cozy@yamaguchi-u.ac.jp (T.S.) \\ 2 Engineering Center for Orthopaedic Research Excellence (E-CORE), Departments of Bioengineering \\ and Orthopaedics, The University of Toledo, Toledo, OH 43606, USA; \\ Muzammil.Mumtaz@rockets.utoledo.edu (M.M.); Sudharshan.Tripathi@rockets.utoledo.edu (S.T.); \\ Amey.Kelkar@rockets.utoledo.edu (A.K.) \\ * Correspondence: Vijay.Goel@utoledo.edu; Tel.: +1-(419)-530-8035
}

check for updates

Citation: Nishida, N.; Mumtaz, M.; Tripathi, S.; Kelkar, A.; Sakai, T.; Goel, V.K. Biomechanical Analysis of Posterior Ligaments of Cervical Spine and Laminoplasty. Appl. Sci. 2021, 11, 7645. https://doi.org/10.3390/ app11167645

Academic Editor: Mark King

Received: 21 July 2021

Accepted: 17 August 2021

Published: 20 August 2021

Publisher's Note: MDPI stays neutral with regard to jurisdictional claims in published maps and institutional affiliations.

Copyright: (C) 2021 by the authors. Licensee MDPI, Basel, Switzerland. This article is an open access article distributed under the terms and conditions of the Creative Commons Attribution (CC BY) license (https:/ / creativecommons.org/licenses/by/ $4.0 /)$.

\begin{abstract}
Cervical laminoplasty is a valuable procedure for myelopathy but it is associated with complications such as increased kyphosis. The effect of ligament damage during cervical laminoplasty on biomechanics is not well understood. We developed the C2-C7 cervical spine finite element model and simulated C3-C6 double-door laminoplasty. Three models were created (a) intact, (b) laminoplasty-pre (model assuming that the ligamentum flavum (LF) between C3-C6 was preserved during surgery), and (c) laminoplasty-res (model assuming that the LF between C3-C6 was resected during surgery). The models were subjected to physiological loading, and the range of motion (ROM), intervertebral nucleus stress, and facet contact forces were analyzed under flexion/extension, lateral bending, and axial rotation. The maximum change in ROM was observed under flexion motion. Under flexion, ROM in the laminoplasty-pre model increased by 100.2\%, $111.8 \%$, and $98.6 \%$ compared to the intact model at C3-C4, C4-C5, and C5-C6, respectively. The ROM in laminoplasty-res further increased by $105.2 \%, 116.8 \%$, and $101.8 \%$ compared to the intact model at $\mathrm{C} 3-\mathrm{C} 4, \mathrm{C} 4-\mathrm{C} 5$, and $\mathrm{C} 5-\mathrm{C} 6$, respectively. The maximum stress in the annulus/nucleus was observed under left bending at the C4-C5 segment where an increase of $139.5 \%$ and $229.6 \%$ compared to the intact model was observed for laminoplasty-pre and laminoplasty-res model, respectively. The highest facet contact forces were observed at C4-C5 under axial rotation, where an increase of 500.7\% and $500.7 \%$ was observed compared to the intact model for laminoplasty-pre and laminoplasty-res, respectively. The posterior ligaments of the cervical spine play a vital role in restoring/stabilizing the cervical spine. When laminoplasty is performed, the surgeon needs to be careful not to injure the posterior soft tissue, including ligaments such as LF.
\end{abstract}

Keywords: laminoplasty; finite element method; ligamentum flavum

\section{Introduction}

Cervical laminoplasty is a decompression procedure of the lamina for asymptomatic patients of cervical spondylotic myelopathy (CSM), cervical disc herniation (CDH), and cervical ossification of the posterior longitudinal ligament (C-OPLL) [1-4]. The primary purpose of laminoplasty is to decompress the cervical spinal cord by widening the spinal canal, preserving the posterior anatomical structures as much as possible, and preserving the widened space stability [1]. It is a technique with excellent clinical and mechanical results $[1,5,6]$. Laminoplasty is divided into two types based on osteotomy: (1) Doubledoor laminoplasty and (2) open-door laminoplasty [1]. In double-door laminoplasty, the osteotomy is performed at the central lamina. In open-door laminoplasty, the osteotomy 
is performed at one side of the lamina. Both techniques are associated with reasonable clinical outcomes [7].

However, some authors have reported increased kyphosis and axial pain postoperatively [8-10] due to the damage to the posterior cervical muscles and ligaments during the surgical procedure [8-11]. Concerning these papers, few reports have examined the extent of biomechanical changes when laminoplasty with/without LF is performed on the cervical spine [12-14]. The LF was reported to restrain flexion equally in a porcine model [15]. In the biomechanical study, none of the studies reported the effect of preserving/resecting the LF. In a clinical study, Duetzmann reported postoperative axial pain as prevalent in up to $30 \%$ of the patients by injured LF [11]. The development of techniques to preserve the posterior ligaments has been reported [16-19]. We hypothesize that when laminoplasty is conducted on the cervical spine model, the range of motion (ROM) and stress concentrations on the cervical spine may change with/without the LF, and the importance of posterior ligament for restoring/stabilizing the cervical spine will become evident.

For this purpose, the C2-C7 three-dimension (3D) finite element (FE) model of the cervical spine was developed using CT scans of a healthy subject. The 3D FE model of the cervical spine was validated for ROM, intervertebral nucleus stress, and facet contact forces by comparing data with in vitro experiments. Later, the validated model was modified to simulate laminoplasty with and without LF.

\section{Material and Methods}

\subsection{Model Development}

A 3D FE model of the cervical spine (C2-C7) was created based on the computed tomography (CT) of a 22-year-old healthy adult subject. The ethics committee approved the use of these images at the Center for Clinical Research of the corresponding author's hospital, and written informed consent was obtained. The geometry of the vertebrae was reconstructed using the $\mathrm{CT}$ scans which were used for reconstructing the geometry of intervertebral discs. The 3D reconstruction of cervical spine geometry from CT scans was carried out using the image segmentation software MIMICS 15. 0 (Materialise, Leuven, Belgium). The reconstructed geometry of hard and soft tissues was meshed with the hexahedral elements using the IA-FE MESH software (Iowa, United States). The meshed vertebrae/discs were exported to the ABAQUS software 6. 14 (Dassault Systèmes, Simulia Inc., Providence, RI, USA) to assemble the $\mathrm{C} 2-\mathrm{C} 7$ cervical spine. The following ligaments were added to the model, anterior longitudinal ligament (ALL), posterior longitudinal ligament (PLL), interspinous ligament (ISL), supraspinous ligament (SSL), capsular ligament (CL), and LF using connector elements in ABAQUS. The outer $0.5 \mathrm{~mm}$ layer of the vertebrae represented a cortical shell, and the inside represented a cancellous bone. The intervertebral discs were composed of annulus fibrosus (50\%) and nucleus pulposus $(50 \%)$. The annulus consisted of a ground substance along with embedded fibers oriented at $\pm 25^{\circ}$ [20]. The facet joints in the model were represented using the surface-surface sliding contact, whereas the Lushka's joints in the lower cervical intervertebral discs were modeled using GAPUNI elements [21]. The material properties for all the structures in the FE model were taken from the literature summarized in Table $1[22,23]$.

Figure 1 represents the intact model having 213,165 elements and 173,215 nodes. 
Table 1. Material properties assigned to the finite element model [21-25].

\begin{tabular}{|c|c|c|c|c|}
\hline Component & Material Properties & Constitute Relation & Element Type & Area $\left(\mathrm{mm}^{2}\right)$ \\
\hline \multicolumn{5}{|c|}{ Bone [25] } \\
\hline Vertebral cortical bone & $\begin{array}{c}\mathrm{E}=10,000 \mathrm{MPa} \\
\mathrm{v}=0.3\end{array}$ & Isotropic, Elastic & C3D8 & - \\
\hline Vertebral cancellous bone & $\begin{array}{c}\mathrm{E}=450 \mathrm{MPa} \\
\mathrm{v}=0.25\end{array}$ & Isotropic, Elastic & C3D8 & - \\
\hline Vertebrae-Posterior & $\begin{array}{c}\mathrm{E}=3500 \mathrm{MPa} \\
\mathrm{v}=0.25\end{array}$ & Isotropic, Elastic & C3D10 & - \\
\hline Artificial bone & $\begin{array}{c}\mathrm{E}=10,000 \mathrm{MPa} \\
\mathrm{v}=0.3\end{array}$ & Isotropic, Elastic & C3D8 & - \\
\hline \multicolumn{5}{|c|}{ Intervertebral Disc [24] } \\
\hline $\begin{array}{l}\text { Ground substance of } \\
\text { annulus fibrosis }\end{array}$ & $\begin{array}{l}\mathrm{C} 10=0.7 \\
\mathrm{C} 01=0.2\end{array}$ & Hyper-elastic, Mooney-Rivlin & C3D8 & - \\
\hline Nucleus pulposus & $\begin{array}{c}\mathrm{C} 10=0.12 \\
\mathrm{C} 01=0.03 \\
\mathrm{D} 1=0\end{array}$ & $\begin{array}{c}\text { Incompressible Hyper-elastic, } \\
\text { Mooney-Rivlin }\end{array}$ & C3D8 & - \\
\hline \multicolumn{5}{|c|}{ Ligaments [23] } \\
\hline $\begin{array}{l}\text { Anterior Longitudinal } \\
\text { Ligament }\end{array}$ & $\begin{array}{c}15.0(<12 \%), 30.0(>12 \%) \\
\mathrm{v}=0.3\end{array}$ & Non-linear, Hypo-elastic & T3D2 & 6.1 \\
\hline $\begin{array}{l}\text { Posterior Longitudinal } \\
\text { Ligament }\end{array}$ & $\begin{array}{c}10.0(<12 \%), 20.0(>12 \%) \\
\mathrm{v}=0.3\end{array}$ & Non-linear, Hypo-elastic & T3D3 & 5.4 \\
\hline Capsular Ligament & $\begin{array}{c}7.0(<30 \%), 30(>12 \%) \\
\mathrm{v}=0.3\end{array}$ & Non-linear, Hypo-elastic & T3D4 & 46.6 \\
\hline Ligamentum Flavum & $\begin{array}{c}5.0(<25 \%), 10.0(>25 \%) \\
\mathrm{v}=0.3\end{array}$ & Non-linear, Hypo-elastic & T3D5 & 50.1 \\
\hline Interspinous Ligament & $\begin{array}{c}4.0(20-40 \%), 8.0(>40 \%) \\
\mathrm{v}=0.3\end{array}$ & Non-linear, Hypo-elastic & T3D6 & 13.1 \\
\hline \multicolumn{5}{|c|}{ Facet Joints [21] } \\
\hline Apophyseal Joints & $\begin{array}{c}\text { Non-linear } \\
\text { Soft contact, } \\
\text { GAPPUNI elements }\end{array}$ & - & - & - \\
\hline
\end{tabular}
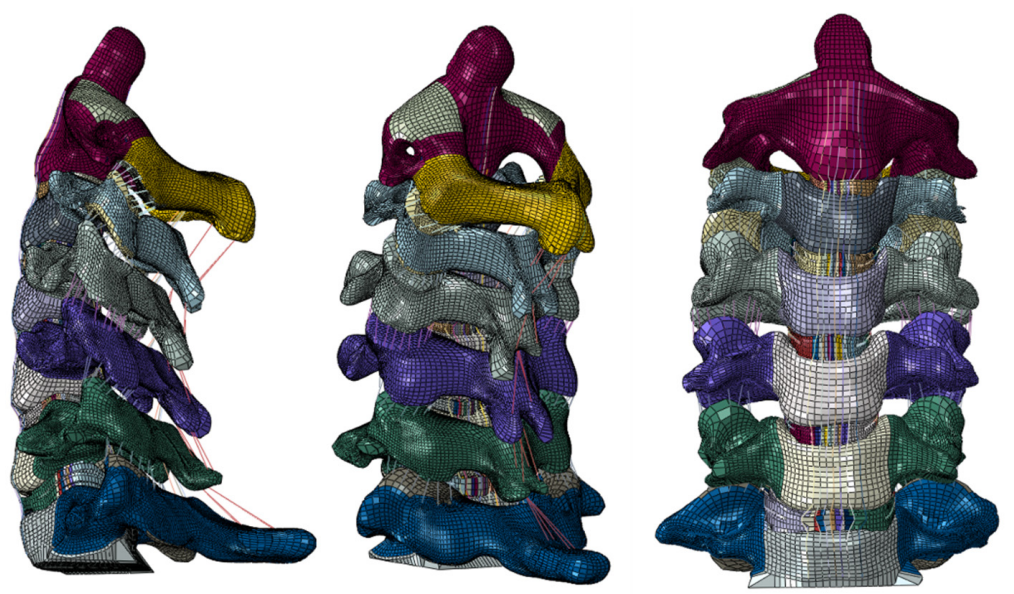

Figure 1. The intact (C2-C7) finite element model.

\subsection{Model Validation}

The intact $\mathrm{C} 2-\mathrm{C} 7$ model was validated using the in vitro loading protocol documented by Finn et al. [25]. A pure moment of $1.5 \mathrm{Nm}$ was applied to the odontoid process of the 
$\mathrm{C} 2$ vertebra in flexion/extension, lateral bendings, and axial rotations [25]. Furthermore, the caudal endplate of the $\mathrm{C} 7$ vertebra was fixed by suppressing all six degrees of freedom. The effects of muscular contractions and the weight of the skull were replicated using the follower load method by applying a connector force of $100 \mathrm{~N}$. The ROM, intervertebral nucleus stress, and facet contact forces were computed for each level in flexion/extension, lateral bendings, and axial rotations and were compared with the published in vitro data in the literature by Finn et al. [25], Pospiech et al. [24], Kretzer et al. [26], and Patel et al. [27].

\subsection{Cervical Laminoplasty}

Clinically, both laminoplasty (double-door and open-door) methods have shown similar results [7]. However, authors practice double-door laminoplasty clinically, thus they opted to simulate it. Double-door laminoplasty was simulated by performing osteotomy at the central spinous process and lamina. First, the ISL and SS were resected. Afterwards, the spinous process was partially resected, about $4 \mathrm{~mm}$ of bone from the center of the lamina was cut, the medial side of both the facet joints was shaved so that the lamina could be opened. The LF of $\mathrm{C} 2-\mathrm{C} 3$ and $\mathrm{C} 6-\mathrm{C} 7$ was resected since these interfered with the opening of the lamina. However, the LF of C3-C6 segment was preserved. The lamina was opened to the right and left sides. Moreover, it widened the narrow canal and decompressed the spinal cord region posteriorly.

The artificial bone with $4 \mathrm{~mm}$ height and $8 \mathrm{~mm}$ depth was then placed to fit the opened lamina (Figure 2). The material properties of the artificial bone were the same as the cortical bone. The artificial bone was connected to the lamina using the "TIE" constraint in Abaqus software.

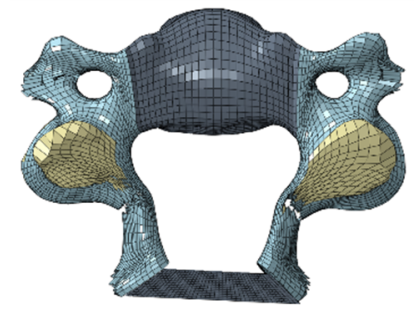

(a)

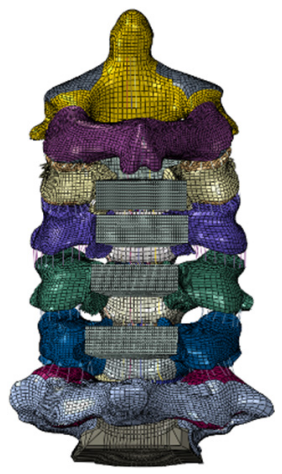

(b)

Figure 2. (a) Axial view of double-door laminoplasty at C4, (b) C2-C7 model with laminoplasty from C3-C6.

This model, in which the LF of C3-C6 segment was preserved, was used as the laminoplasty-pre model (C3-C6 laminoplasty with LF preserved). The model, in which the LF of C3-C6 segment of laminoplasty-pre model was resected, was then created as the laminoplasty-res model.

\subsection{Loads and Boundary Conditions}

The pure moment of $1.5 \mathrm{Nm}$ was applied to the C2 odontoid process to simulate flexion/extension, lateral (left and right) bendings, and axial (left and right) rotations. Additionally, the inferior endplate of the C7 was fixed. The model was subjected to the compressive follower load of $100 \mathrm{~N}$ to represent the weight of the head and cervical muscle contractions.

\subsection{Data Analyses}

The ROM, intervertebral nucleus stress, and facet contact forces were calculated for the intact, laminoplasty-pre, and laminoplasty-res models. The ROM for each functional 
spinal unit (FSU) was quantified by subtracting the absolute rotation of the upper vertebra from the lower vertebra. For nucleus stress, the highest value for maximum von Mises stress was observed on the nucleus to analyze the effect of surgery on the nucleus of the intervertebral disc as done by Tsuang et al. [28]. For the facet joint contact force, the data for facet forces were averaged for the left/right facets.

\section{Results}

\subsection{Model Validation}

ROM

The intact cervical spine model demonstrated ROM in flexion/extension, lateral bending, and axial rotations within the range of the in vitro ROM data published by Finn et al. (Figure 3) [25].

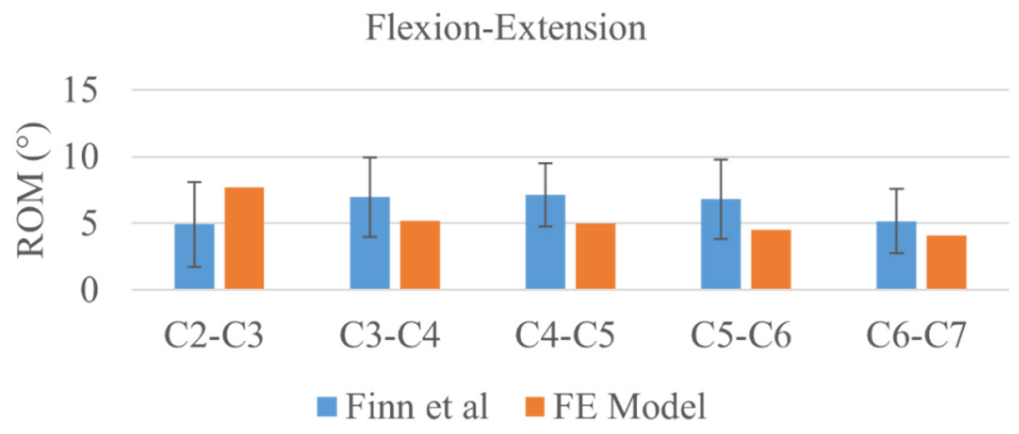

(a)

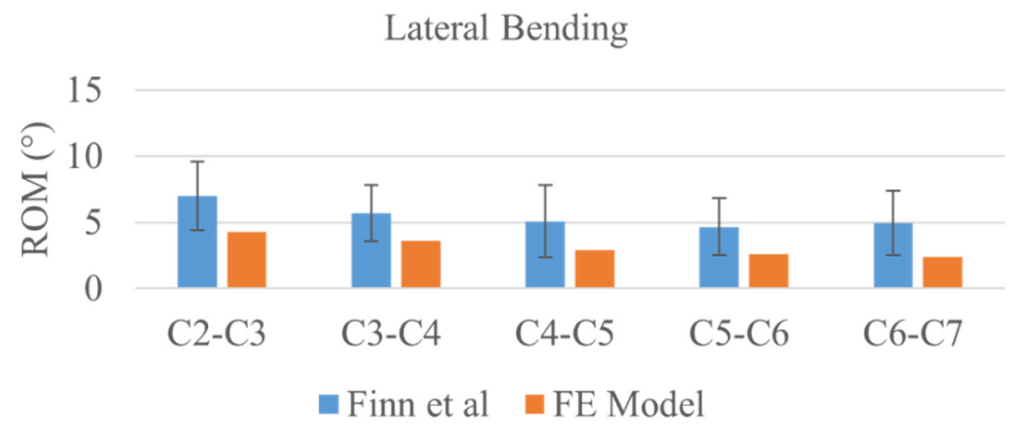

(b)

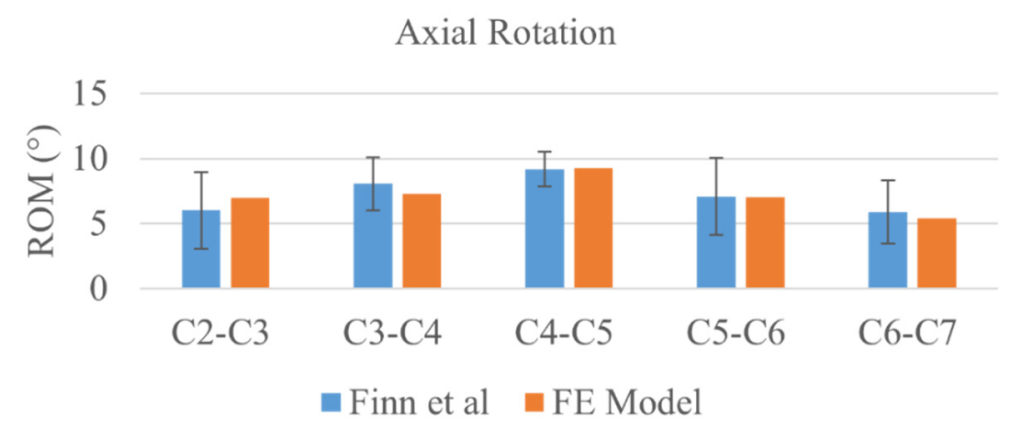

(c)

Figure 3. (a) Comparison of the flexion-extension motion between the FE model results and the results reported in the literature [25]. (b) Comparison of the lateral bending motion between the FE model results and the results reported in the literature [25]. (c) Comparison of the axial rotation motion between the FE model results and the results reported in the literature [25]. 


\subsection{Intervertebral Nucleus Stress}

The intact $\mathrm{C} 2-\mathrm{C} 7$ cervical spine model demonstrated intervertebral nucleus stress in flexion/extension, lateral bending, and axial rotations within the range of the in vitro data documented by Kretzer et al. and Pospiech et al. [24,26]. Unfortunately, no documented in vitro intervertebral nucleus stress data were available for comparison for the C4-C5 level in the published literature (Table 2; Figure 4).

Table 2. Comparison of the intervertebral nucleus stress between the FE model results and the in vitro results reported in the literature $[24,26]$.

\begin{tabular}{|c|c|c|c|c|c|c|}
\hline \multirow{2}{*}{ Segment } & \multicolumn{6}{|c|}{ Intervertebral Nucleus Stress (MPa)_FE Model } \\
\hline & Flexion & Extension & Left Bending & Right Bending & Left Rotation & Right Rotation \\
\hline $\mathrm{C} 2-\mathrm{C} 3$ & 0.26 & 0.35 & 0.23 & 0.22 & 0.27 & 0.26 \\
\hline $\mathrm{C} 3-\mathrm{C} 4$ & 0.17 & 0.14 & 0.14 & 0.15 & 0.19 & 0.24 \\
\hline $\mathrm{C} 4-\mathrm{C} 5$ & 0.21 & 0.16 & 0.11 & 0.17 & 0.22 & 0.21 \\
\hline C5-C6 & 0.17 & 0.12 & 0.1 & 0.14 & 0.18 & 0.18 \\
\hline $\mathrm{C} 6-\mathrm{C} 7$ & 0.11 & 0.14 & 0.09 & 0.11 & 0.1 & 0.13 \\
\hline \multirow{2}{*}{ Segment } & \multicolumn{6}{|c|}{ Intervertebral Nucleus Stress (MPa)-In Vitro } \\
\hline & Flexion & Extension & Left Bending & Right Bending & Left Rotation & Right Rotation \\
\hline $\mathrm{C} 2-\mathrm{C} 3$ & $0.08-0.36$ & $0.08-0.36$ & $0.12-0.36$ & $0.12-0.36$ & - & - \\
\hline $\mathrm{C} 3-\mathrm{C} 4$ & $0.12-0.43$ & $0.12-0.43$ & $0.08-0.31$ & $0.08-0.31$ & $0.14-0.36$ & $0.14-0.36$ \\
\hline C4-C5 & - & - & - & - & - & - \\
\hline C5-C6 & $0.01-0.56$ & $0.01-0.56$ & $0.01-0.38$ & $0.01-0.38$ & $0.04-0.49$ & $0.04-0.49$ \\
\hline $\mathrm{C} 6-\mathrm{C} 7$ & $0.01-0.17$ & $0.01-0.17$ & $0.01-0.11$ & $0.01-0.11$ & - & - \\
\hline
\end{tabular}

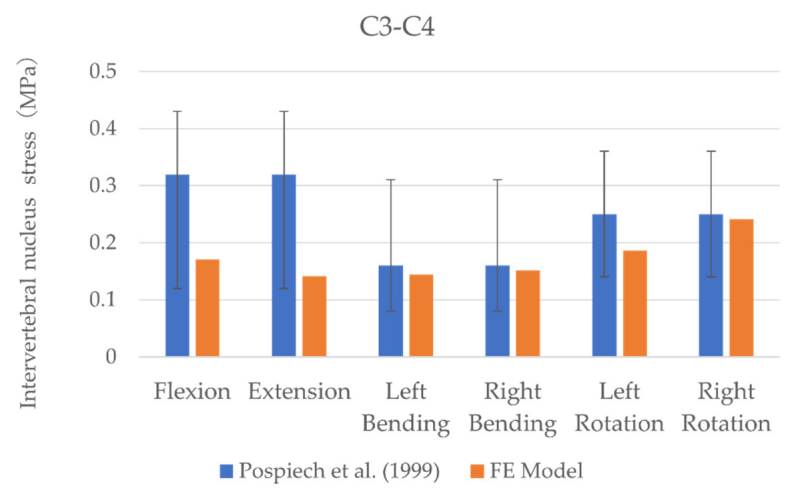

(a)

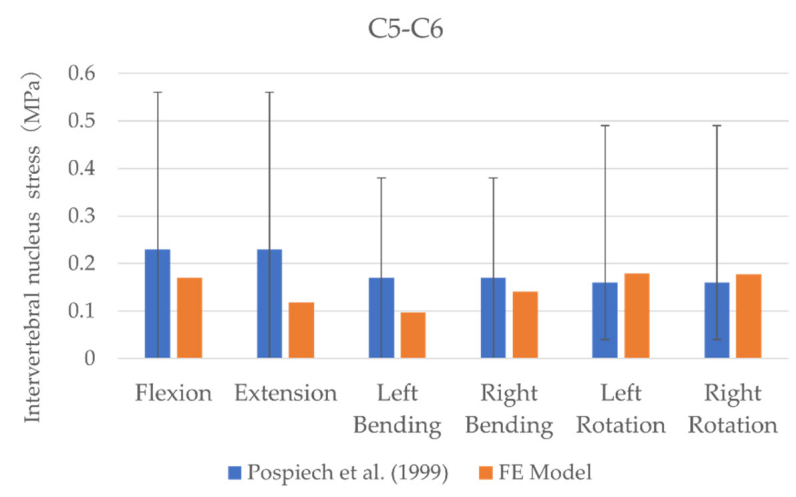

(b)

Figure 4. (a) Comparison of the intervertebral nucleus stress at C3-C4 between the FE model results and the results reported in the literature [24]. (b) Comparison of the intervertebral nucleus stress at C5-C6 between the FE model results and the results reported in the literature [24]. 


\subsection{Facet Contact Force}

The C2-C7 cervical spine model exhibited facet forces in extension, lateral bending, and axial rotations for those levels in the range of in vitro facet contact force data published by Patel et al. (Table 3; Figure 5). Unfortunately, no in vitro data for facet forces for C2-C3, C5-C6, and C6-C7 levels were available for comparison.

Table 3. Comparison of the facet contact forces between the FE model results and the in vitro results reported in the literature [27].

\begin{tabular}{ccccccc}
\hline \multirow{2}{*}{ Segment } & \multicolumn{2}{c}{ Facet Contact Forces (N)-FE Model } & \multicolumn{2}{c}{ Facet Contact Forces (N)-In Vitro } \\
\cline { 2 - 7 } & Extension & Lateral Bending & Axial Rotation & Extension & Lateral Bending & Axial Rotation \\
\hline C2-C3 & 50.9 & 45.6 & 21.3 & - & - & - \\
C3-C4 & 42.6 & 34.2 & 36.2 & $12.5-62.5$ & $29.5-81.2$ & $34.5-88.1$ \\
C4-C5 & 31.4 & 35.8 & 20.7 & $13.9-43.9$ & $36.2-74.8$ & $34.7-88.2$ \\
C5-C6 & 32.4 & 34.6 & 34.7 & - & - & - \\
C6-C7 & 24.6 & 31.9 & 28.4 & - & - \\
\hline
\end{tabular}

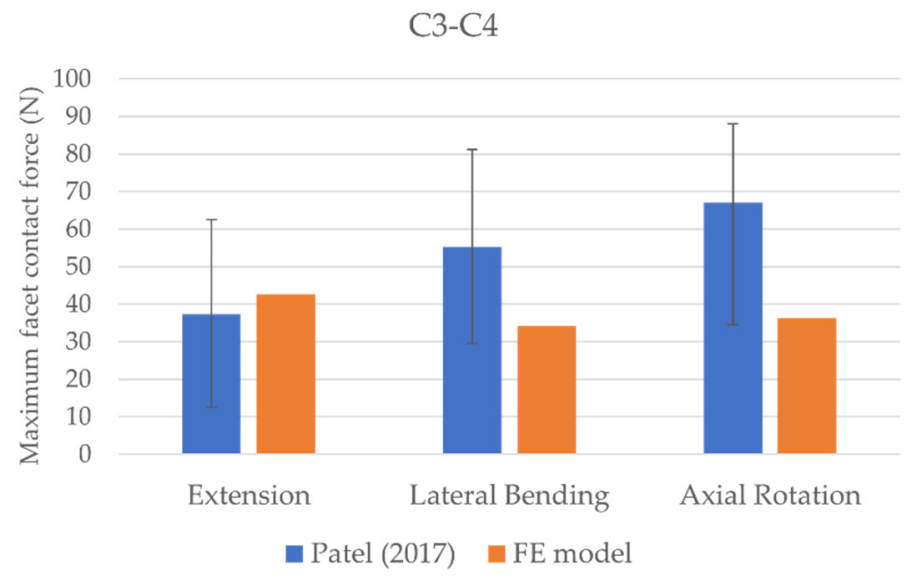

(a)

C4-C5

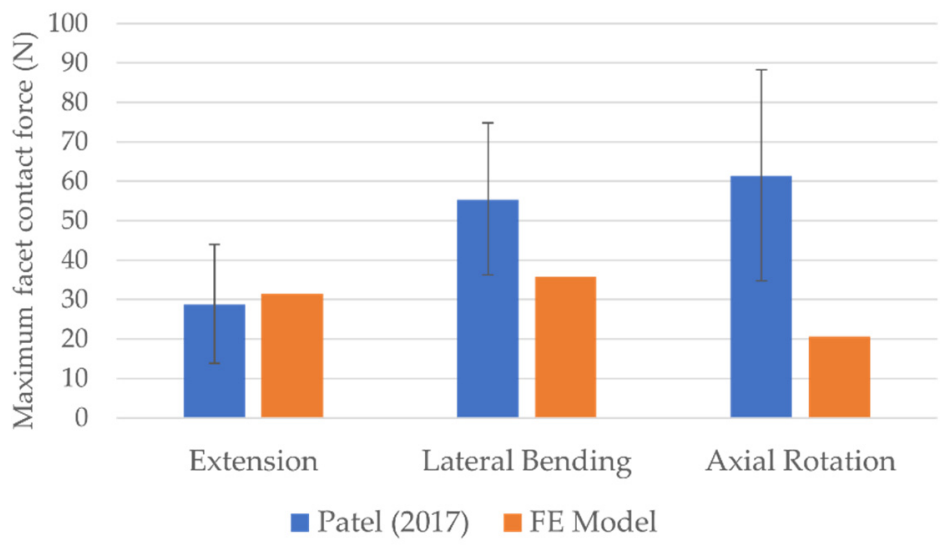

(b)

Figure 5. (a) Comparison of the facet contact forces at C3-C4 between the FE model results and the in vitro results reported in the literature [27]. (b) Comparison of the facet contact forces at C4-C5 between the FE model results and the in vitro results reported in the literature [27]. 


\subsection{Comparison of Intact and the Laminoplasty Models $\mathrm{ROM}$}

In the extension, both laminoplasty-pre and laminoplasty-res models show similar ROM results for C3-C4 and C4-C5 levels. ROMs were significantly decreased by $54.3 \%$ and $8.2 \%$, respectively at $\mathrm{C} 3-\mathrm{C} 4$ and $\mathrm{C} 4-\mathrm{C} 5$ levels than the intact model. At the same time, for flexion motion at $\mathrm{C} 3-\mathrm{C} 4$ and $\mathrm{C} 4-\mathrm{C} 5$ levels, the laminoplasty-pre model increased ROMs by $100.2 \%$ and $111.8 \%$, respectively than intact. While for the laminoplasty-res model, it was increased by $105.2 \%$ and $116.8 \%$, respectively for C3-C4 and C5-C6 levels than intact. In left bending and the laminoplasty-pre and laminoplasty-res models, ROM significantly reduced at the $\mathrm{C} 3-\mathrm{C} 4$ and $\mathrm{C} 4-\mathrm{C} 5$ levels by $77.2 \%$ and $9.7 \%$, respectively than intact. In contrast, for right bending, the ROM at the $\mathrm{C} 2-\mathrm{C} 3$ level increased by $135.3 \%$ and decreased at the $\mathrm{C} 4-\mathrm{C} 5, \mathrm{C} 5-\mathrm{C} 6$, and $\mathrm{C} 6-\mathrm{C} 7$ levels by $87.1 \%$, $90.5 \%$, and $12.4 \%$, respectively than the intact model. For left and right rotation, the ROM of C4-C5 was decreased in laminoplasty-pre and laminoplasty models-res than in the intact model by $86.1 \%$ and $76.9 \%$, respectively than intact (Figure 6).

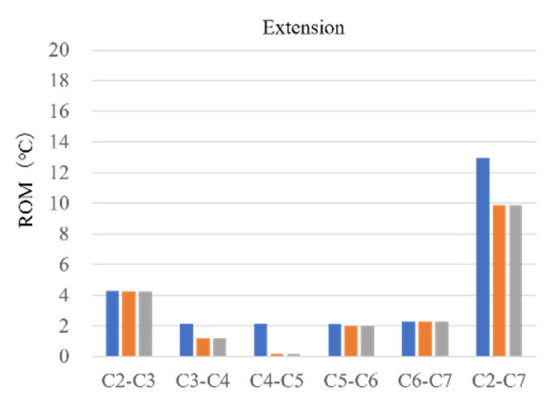

(a)

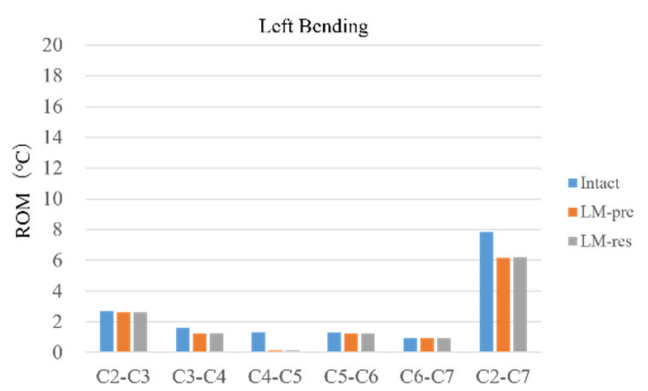

(c)

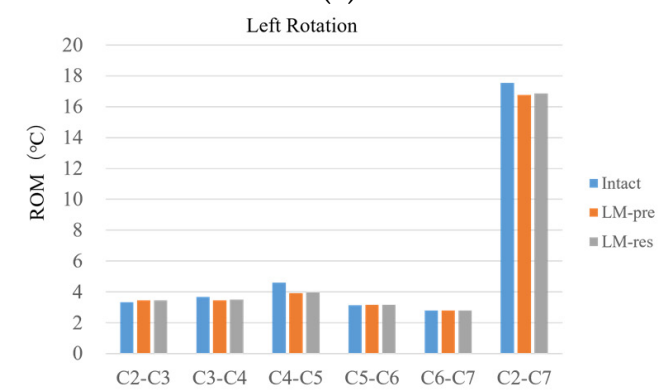

(e)

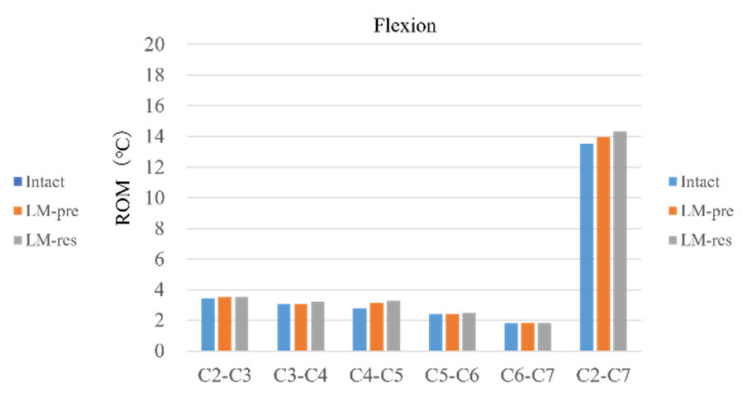

(b)

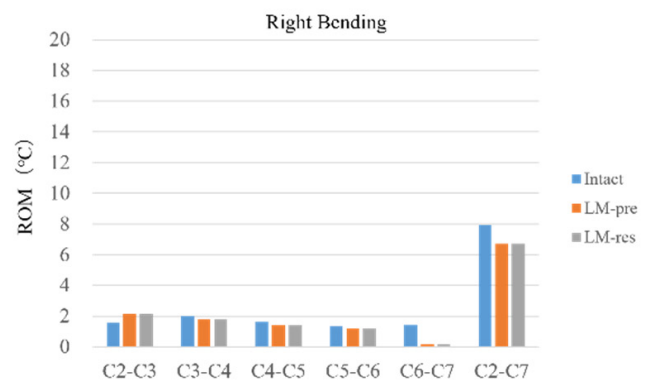

(d)

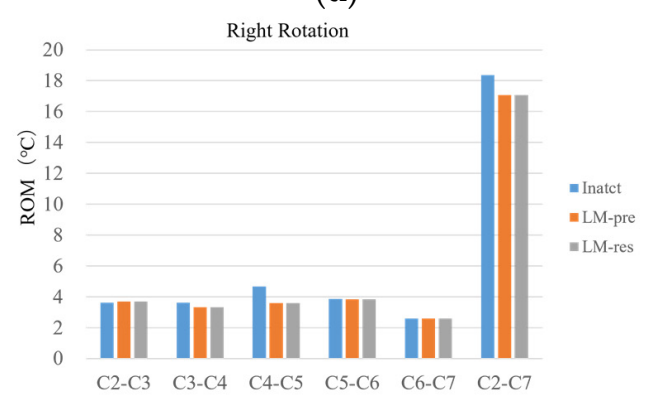

(f)

Figure 6. Range of motion. (a) Extension, (b) flexion, (c) left bending, (d) right bending, (e) left rotation, and (f) right rotation. The vertical axis is an angle (degree), the horizontal axis is each intervertebral level. 


\subsection{Intervertebral Nucleus Stress}

In extension, intervertebral nucleus stress between C4-C5 was significantly increased in laminoplasty-pre and laminoplasty-res models than in the intact model by $114.2 \%$. For flexion, intervertebral nucleus stress between C4-C5 was significantly increased in laminoplasty-pre and especially laminoplasty-res models than in the intact model by $101.8 \%$ and $105.3 \%$, respectively. In lateral (left and right) bending and right rotation, the intervertebral nucleus stress of the nucleus between C4-C5 was significantly increased in laminoplasty-pre by $139.4 \%, 111.5 \%$, and $123.3 \%$, respectively and laminoplasty-res models by $139.5 \%, 111.7 \%$, and $123.4 \%$, respectively than in the intact model (Figure 7 ).

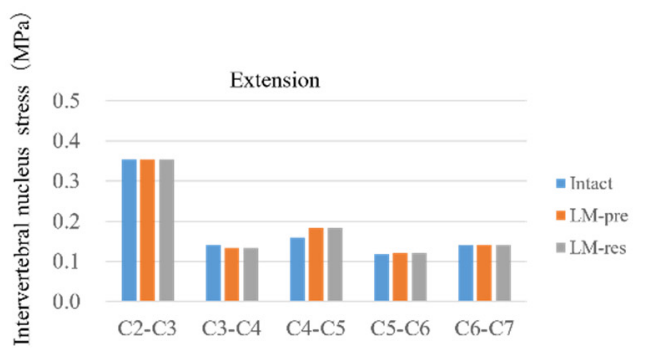

(a)

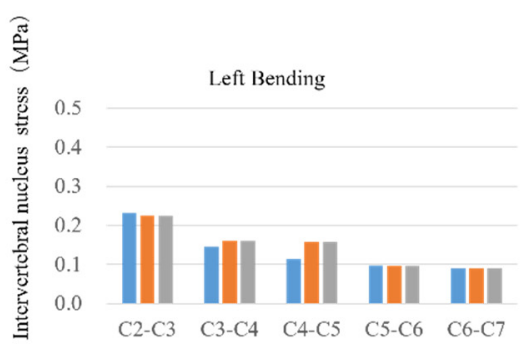

(c)

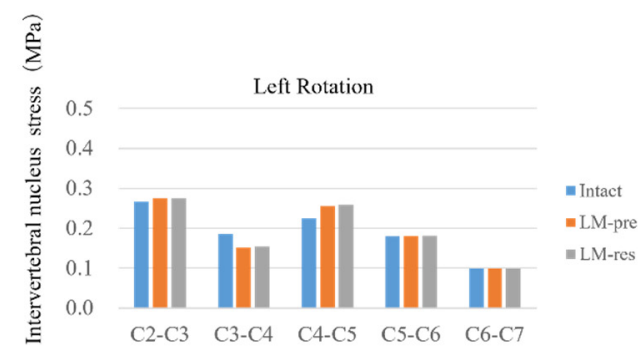

(e)

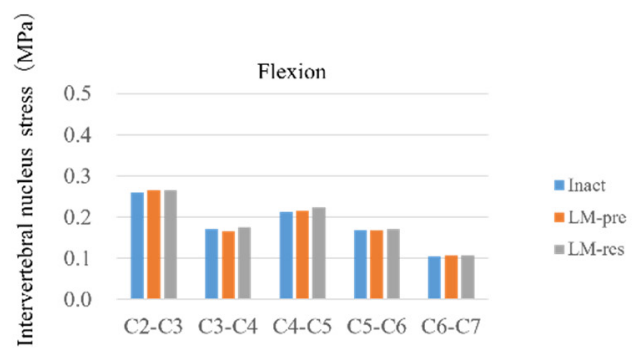

(b)

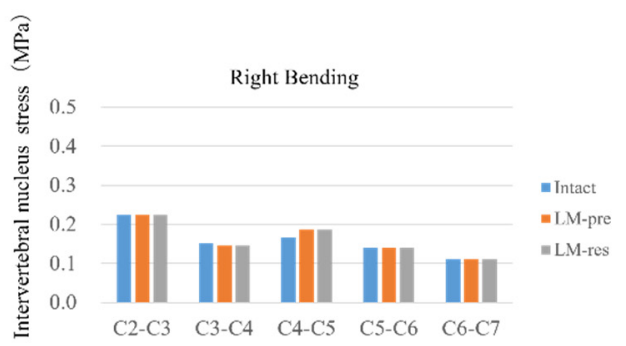

(d)

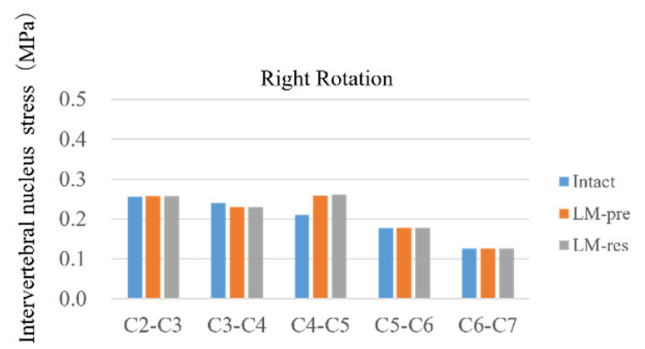

(f)

Figure 7. Intervertebral nucleus stress in (a) extension, (b) flexion, (c) left bending, (d) right bending, (e) left rotation, and (f) right rotation. The vertical axis is stress (MPa), the horizontal axis is each intervertebral level.

\subsection{Facet Contact Forces}

In extension, facet contact forces of C3-C4 and C4-C5 levels were increased by $133 \%$ and $361.7 \%$, respectively in laminoplasty-pre and laminoplasty-res models compared to the intact model.

In lateral bending, facet contact forces of $\mathrm{C} 3-\mathrm{C} 4$ and $\mathrm{C} 4-\mathrm{C} 5$ levels were increased by $131 \%$ and $256.3 \%$, respectively in laminoplasty-pre and laminoplasty-res models compared to the intact model.

In axial rotation, facet contact forces of $\mathrm{C} 3-\mathrm{C} 4$ and $\mathrm{C} 4-\mathrm{C} 5$ levels were increased by $140.7 \%$ and $500.7 \%$, respectively in laminoplasty-pre and laminoplasty-res models compared to the intact (Figure 8). 


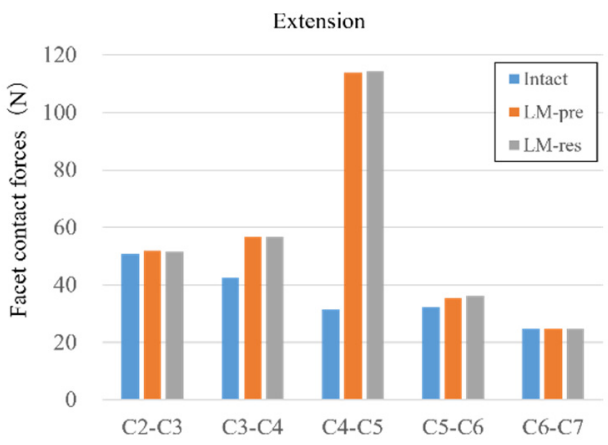

(a)

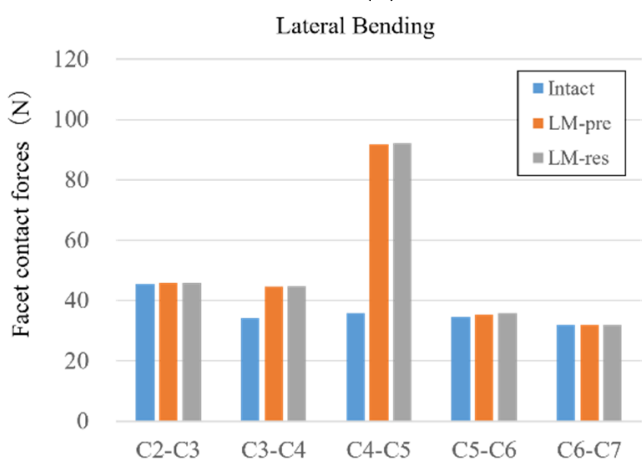

(b)

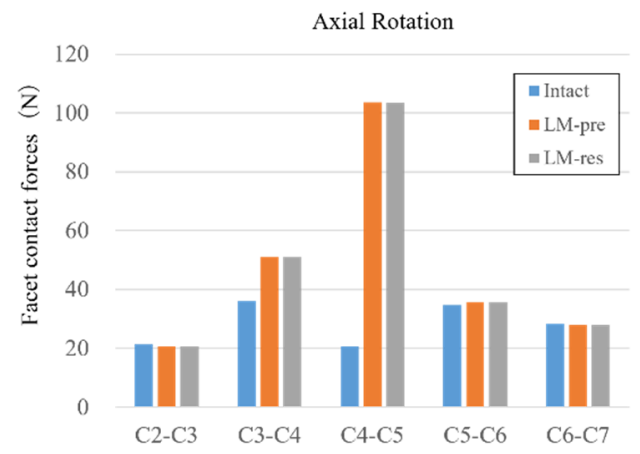

(c)

Figure 8. Facet contact forces. (a) Extension, (b) lateral bending, (c) axial rotation. Vertical axis is force $(\mathrm{N})$, horizontal axis is each intervertebral level.

\section{Discussion}

This study aimed to investigate the laminoplasty with/without LF of posterior ligaments on the cervical spine biomechanics using a validated model of $\mathrm{C} 2-\mathrm{C} 7$ spine.

There are two types of spinal cord injuries for CSM, CDH, and C-OPLL: Static and dynamic compression. The causes for static damage include congenital spinal stenosis, cervical disc herniation, osteophytosis, and ligamentous hypertrophy $[29,30]$. The causes for dynamic compression injury include translation and angulation of the spinal column or overlapping of the lamina (pincer mechanism) and buckling of the ligamentum flavum (LF) [31-33]. Laminoplasty as extensive posterior decompression is suitable for cervical spinal cord myelopathy resulting from static and dynamic compression.

Modifications in the current procedures are being suggested by clinicians to address the current surgical complications for the increased kyphosis and axial pain. In recent years, minimally invasive methods for laminoplasty, such as selective laminoplasty, skip laminectomy, and endoscopic laminectomy, have been reported and have shown promising clinical outcomes [17-19,34-36]. Hirabayashi reported on the development of double-door 
laminoplasty. At first, a pyramidal-shaped osteotomy is made at the cranial base of the spinous process to obtain a good visual field. Next, the remaining part of the spinous process is split centrally from its surface, and the split portion is connected to the pyramidalshaped dome [16]. Minamide conducted articular segmental decompression surgery using endoscopy (cervical microendoscopic laminotomy) for cervical spondylotic myelopathy and reported patients to have similar neurological outcomes to conventional laminoplasty, with significantly less postoperative axial pain and improved subaxial cervical lordosis [17]. Shiraishi proposed a skip laminectomy method that preserved the attachments of the semispinalis cervicis and multifidus muscles on the cervical spinous processes and limited the damage to the attachments of the interspinous and rotator muscles [18]. Kanchiku proposed performing selective laminoplasty on subjects diagnosed with CSM at a single intervertebral level or two consecutive intervertebral levels based on preoperative neurological symptoms and imaging findings. They concluded that the clinical outcomes of selective laminoplasty were similar to the C3-C7 laminoplasty with significantly less operation time and blood loss, compared with conventional C3-C7 laminoplasty [19]. The fundamental purpose of these techniques is to figure out ways on how to avoid damaging the posterior soft tissues, including ligaments. The studies of injuring the posterior ligamentous structures of the cervical spine indicated that each structure contributes to cervical stability [14,37]. The SS, IS, and LF were reported to restrain flexion equally in a porcine model [15]. However, there has been no FE model analysis of the effect of damaging the posterior ligaments on the cervical spine in laminoplasty.

Studying the biomechanics of laminoplasty of the cervical spine can be divided into the FE model and cadaver analysis. However, there are few analyses of laminoplasty models in the literature. Stoner compared intact, laminectomy, and double-door laminoplasty models for spinal cord [38]. Tejapongvorachai reported that the stabilities of the hinge sides of plate-augmented open-door laminoplasties based on cutting in a curved or straight line were compared using a FE model and the potential of the proposed technique to reduce the risk of hinge fracture and displacement [39]. Khuyagbaatar analyzed biomechanical changes in the spinal cord and nerve roots following the open-door and double-door laminoplasty for OPLL [40]. However, none of the studies have reported on the effect of preserving/resecting the LF ligament.

In cadaver research, there are few papers on cervical laminoplasty. Kubo reported that 3D kinematics changes after double-door cervical laminoplasty, with and without the spacer, were studied in a human cadaveric model and the use of hydroxyapatite spacer well contributes to maintaining the total stiffness of cervical spine [41]. Subramaniam reported that open-door laminoplasty leaves the spine in a significantly more stable condition than laminectomy compared with biomechanical stability during flexion and extension [42]. Kode analyzed five human cadaveric specimens with laminoplasty at C5-C6, laminoplasty at C3-C6, and laminectomy. Laminoplasty was closer to intact than laminectomy, and there was no significant difference in laminoplasty, but laminoplasty at C3-C6 was associated with greater motion in lateral bending and axial rotation [43]. However, they did not report on the role of LF in laminoplasty/laminectomy.

To study the effect of preserving/resecting LF in laminoplasty, the FE model of cervical spine was developed and validated. The model was considered validated as ROM, intervertebral nucleus stress, and facet force were all within the range of the experimental results of the in vitro data. Some differences for average data of cadaver about ROM, intervertebral nucleus stress, and facet loads, and our results were considered acceptable due to the higher mean age and possible deformed cervical spine in the cadaver. It will be necessary to compare the FE model analysis with the experiments of any individual in the future. In this laminoplasty-pre and laminoplasty-res analysis, the ROM of C2-C7 was decreased except for flexion. Seichi et al. reported that mean mobility decreased from 36 to $8^{\circ}$ following double-door laminoplasty [44]. Ratliff and Cooper reported that the range of motion was reduced by $46 \%$ for open-door laminoplasty and $50 \%$ for double-door 
laminoplasty relative to pre-operation [45]. Thus, these suggest that the laminoplasty affects stability, and the results of this study were in agreement with the literature.

On the other hand, the increased mobility in flexion suggests that posterior ligament may be one of the causes of post-operative kyphosis. The intervertebral nucleus stress and facet force stress were higher at $\mathrm{C} 4-\mathrm{C} 5$ and were elevated in laminoplasty-pre and laminoplasty-res than the intact model. There are no papers that have experimentally verified the stress on the disc and facet of laminoplasty. However, the clinical and radiological analysis of the ROM of the cervical vertebrae indicate that when the stability of the caudal vertebrae increases, the mobility and instability of the cranial side (C3-C4, C4-C5) also increases [46,47]. In the present analysis, the bottom of C7 was fixed, and due to the increased stability of laminoplasty, the load of the cervical vertebrae was considered to be concentrated in the cranial side (C3-C4, C4-C5).

There are several limitations to our study. It does not include the trapezius or other muscles. Spine alignment was lordotic only. This model simulates an immediate postoperative scenario and does not consider conditions such as fusion and non-fusion of the lamina, and does not fully simulate the long-term condition of laminoplasty. The LF covered the interlaminar space. In the present model, it is impossible to conclude the mechanical characteristics of the partial or total resection of LF for laminoplasty [48]. Although there are several methods of laminoplasty [49], this paper only analyzes double-door laminoplasty. This study does not consider the change in material property that may be altered by osteoporosis or osteoarthritis.

Despite these limitations, this study provides valuable insights on the effect of preserving/resecting the LF during laminoplasty.

\section{Conclusions}

The FE model created from medical images was used to analyze the effects of preserving/resecting LF in the laminoplasty procedure. This study concluded that laminoplasty alters the intervertebral mobility. Moreover, the cranial cervical level load increases significantly when the LF is injured, which leads to hyper flexion. In light of the current study, the surgeon should be mindful of the role of LF as well as pay attention to LF resection or injury during laminoplasty.

Author Contributions: Conceptualization, N.N.; data curation, M.M., N.N., and S.T.; formal analysis, M.M., N.N., and S.T.; funding acquisition, V.K.G.; methodology, N.N. and A.K.; project administration, N.N. and M.M.; supervision, T.S.; validation, M.M. and N.N.; visualization, T.S.; writing-original draft, N.N.; writing-review and editing, M.M., N.N., A.K., S.T., and V.K.G. All authors have read and agreed to the published version of the manuscript.

Funding: Work supported in part by the NSF Industry/University Cooperative Research Center at the University of California at San Francisco, University of Toledo, and Ohio State University. Award number: 206965.

Institutional Review Board Statement: The study was conducted according to the guidelines of the Declaration of Helsinki, and approved by the Institutional Review Board of The University of Toledo.

Informed Consent Statement: Informed consent was obtained from the subjects involved in the study.

Data Availability Statement: The data presented in this study are available.

Conflicts of Interest: The authors declare no conflict of interest.

\section{References}

1. Hirabayashi, S.; Kitagawa, T.; Yamamoto, I.; Yamada, K.; Kawano, H. Development and Achievement of Cervical Laminoplasty and Related Studies on Cervical Myelopathy. Spine Surg. Relat. Res. 2020, 4, 8-17. [CrossRef]

2. Boody, B.S.; Lendner, M.; Vaccaro, A.R. Ossification of the posterior longitudinal ligament in the cervical spine: A review. Int. Orthop. 2019, 43, 797-805. [CrossRef]

3. Iyer, A.; Azad, T.D.; Tharin, S. Cervical Spondylotic Myelopathy. Clin. Spine Surg. 2016, 29, 408-414. [CrossRef]

4. Mazas, S.; Benzakour, A.; Castelain, J.E.; Damade, C.; Ghailane, S.; Gille, O. Cervical disc herniation: Which surgery? Int. Orthop. 2019, 43, 761-766. [CrossRef] 
5. Itoh, T.; Tsuji, H. Technical improvements and results of laminoplasty for compressive myelopathy in the cervical spine. Spine 1985, 10, 729-736. [CrossRef]

6. Miyazaki, K.; Kirita, Y. Extensive simultaneous multisegment laminectomy for myelopathy due to the ossification of the posterior longitudinal ligament in the cervical region. Spine 1986, 11, 531-542. [CrossRef]

7. Nagoshi, N.; Yoshii, T.; Egawa, S.; Sakai, K.; Kusano, K.; Nakagawa, Y.; Hirai, T.; Wada, K.; Katsumi, K.; Fujii, K.; et al. Comparison of Surgical Outcomes After Open- and Double-Door Laminoplasties for Patients with Cervical Ossification of the Posterior Longitudinal Ligament: A Prospective Multicenter Study. Spine 2021. [CrossRef]

8. Chen, Q.; Qin, M.; Chen, F.; Ni, B.; Guo, Q.; Han, Z. Comparison of Outcomes Between Anterior Cervical Decompression and Fusion and Posterior Laminoplasty in the Treatment of 4-Level Cervical Spondylotic Myelopathy. World Neurosurg. 2019, 125, e341-e347. [CrossRef]

9. Zhang, J.; Liu, H.; Bou, E.H.; Jiang, W.; Zhou, F.; He, F.; Yang, H.; Liu, T. Comparative Study Between Anterior Cervical Discectomy and Fusion with ROI-C Cage and Laminoplasty for Multilevel Cervical Spondylotic Myelopathy without Spinal Stenosis. World Neurosurg. 2019, 121, e917-e924. [CrossRef]

10. Matsuoka, Y.; Endo, K.; Nishimura, H.; Suzuki, H.; Sawaji, Y.; Takamatsu, T.; Seki, T.; Murata, K.; Konishi, T.; Yamamoto, K. Cervical Kyphotic Deformity after Laminoplasty in Patients with Cervical Ossification of Posterior Longitudinal Ligament with Normal Sagittal Spinal Alignment. Spine Surg. Relat. Res. 2018, 2, 210-214. [CrossRef]

11. Duetzmann, S.; Cole, T.; Ratliff, J.K. Cervical laminoplasty developments and trends, 2003-2013: A systematic review. J. Neurosurg. Spine 2015, 23, 24-34. [CrossRef] [PubMed]

12. Liu, J.; Ebraheim, N.A.; Sanford, C.G., Jr.; Patil, V.; Haman, S.P.; Ren, L.; Yang, H. Preservation of the spinous process-ligamentmuscle complex to prevent kyphotic deformity following laminoplasty. Spine J. 2007, 7, 159-164. [CrossRef]

13. Takeshita, K.; Peterson, E.T.; Bylski-Austrow, D.; Crawford, A.H.; Nakamura, K. The nuchal ligament restrains cervical spine flexion. Spine 2004, 29, E388-E393. [CrossRef]

14. Goel, V.K.; Clark, C.R.; McGowan, D.; Goyal, S. An in-vitro study of the kinematics of the normal, injured and stabilized cervical spine. J. Biomech. 1984, 17, 363-376. [CrossRef]

15. Oxland, T.R.; Panjabi, M.M.; Southern, E.P.; Duranceau, J.S. An anatomic basis for spinal instability: A porcine trauma model. J. Orthop. Res. 1991, 9, 452-462. [CrossRef]

16. Hirabayashi, S. Recent Surgical Methods of Double-door Laminoplasty of the Cervical Spine (Kurokawa's Method). Spine Surg. Relat. Res. 2018, 2, 154-158. [CrossRef]

17. Minamide, A.; Yoshida, M.; Simpson, A.K.; Yamada, H.; Hashizume, H.; Nakagawa, Y.; Iwasaki, H.; Tsutsui, S.; Okada, M.; Takami, M.; et al. Microendoscopic laminotomy versus conventional laminoplasty for cervical spondylotic myelopathy: 5-year follow-up study. J. Neurosurg. Spine 2017, 27, 403-409. [CrossRef]

18. Shiraishi, T.; Fukuda, K.; Yato, Y.; Nakamura, M.; Ikegami, T. Results of skip laminectomy-minimum 2-year follow-up study compared with open-door laminoplasty. Spine 2003, 28, 2667-2672. [CrossRef] [PubMed]

19. Kanchiku, T.; Imajo, Y.; Suzuki, H.; Yoshida, Y.; Nishida, N.; Taguchi, T. Results of surgical treatment of cervical spondylotic myelopathy in patients aged 75 years or more: A comparative study of operative methods. Arch. Orthop. Trauma. Surg. 2014, 134, 1045-1050. [CrossRef]

20. Kallemeyn, N.; Gandhi, A.; Kode, S.; Shivanna, K.; Smucker, J.; Grosland, N. Validation of a C2-C7 cervical spine finite element model using specimen-specific flexibility data. Med. Eng. Phys. 2010, 32, 482-489. [CrossRef]

21. Venkataramana, M.P.; Hans, S.A.; Bawab, S.Y.; Keifer, O.P.; Woodhouse, M.L.; Layson, P.D. Effects of initial seated position in low speed rear-end impacts: A comparison with the TNO rear impact dummy (TRID) model. Traffic Inj. Prev. 2005, 6, 77-85. [CrossRef] [PubMed]

22. Little, J.P.; Adam, C.J.; Evans, J.H.; Pettet, G.J.; Pearcy, M.J. Nonlinear finite element analysis of anular lesions in the L4/5 intervertebral disc. J. Biomech. 2007, 40, 2744-2751. [CrossRef] [PubMed]

23. Goel, V.K.; Clausen, J.D. Prediction of load sharing among spinal components of a C5-C6 motion segment using the finite element approach. Spine 1998, 23, 684-691. [CrossRef]

24. Pospiech, J.; Stolke, D.; Wilke, H.J.; Claes, L.E. Intradiscal pressure recordings in the cervical spine. Neurosurgery 1999, 44, 379-384. [CrossRef] [PubMed]

25. Finn, M.A.; Brodke, D.S.; Daubs, M.; Patel, A.; Bachus, K.N. Local and global subaxial cervical spine biomechanics after single-level fusion or cervical arthroplasty. Eur. Spine J. 2009, 18, 1520-1527. [CrossRef] [PubMed]

26. Kretzer, R.M.; Hsu, W.; Hu, N.; Umekoji, H.; Jallo, G.I.; McAfee, P.C.; Tortolani, P.J.; Cunningham, B.W. Adjacent-level range of motion and intradiscal pressure after posterior cervical decompression and fixation: An in vitro human cadaveric model. Spine 2012, 37, E778-E785. [CrossRef]

27. Patel, V.V.; Wuthrich, Z.R.; McGilvray, K.C.; Lafleur, M.C.; Lindley, E.M.; Sun, D.; Puttlitz, C.M. Cervical facet force analysis after disc replacement versus fusion. Clin. Biomech. 2017, 44, 52-58. [CrossRef] [PubMed]

28. Tsuang, F.Y.; Tsai, J.C.; Lai, D.M. Effect of lordosis on adjacent levels after lumbar interbody fusion, before and after removal of the spinal fixator: A finite element analysis. BMC Musculoskelet. Disord. 2019, 20, 470. [CrossRef]

29. Arnold, J.G., Jr. The clinical manifestations of spondylochondrosis (spondylosis) of the cervical spine. Ann. Surg. 1955, 141, 872-889. [CrossRef]

30. Baptiste, D.C.; Fehlings, M.G. Pathophysiology of cervical myelopathy. Spine J. 2006, 6, 190s-197s. [CrossRef] 
31. Morishita, Y.; Falakassa, J.; Naito, M.; Hymanson, H.J.; Taghavi, C.; Wang, J.C. The kinematic relationships of the upper cervical spine. Spine 2009, 34, 2642-2645. [CrossRef]

32. Taylor, A.R. Mechanism and treatment of spinal-cord disorders associated with cervical spondylosis. Lancet 1953, 1, 717-720. [CrossRef]

33. Penning, L. Some aspects of plain radiography of the cervical spine in chronic myelopathy. Neurology 1962, 12, 513-519. [CrossRef] [PubMed]

34. Kato, Y.; Kojima, T.; Kataoka, H.; Imajo, Y.; Yara, T.; Yoshida, Y.; Imagama, T.; Taguchi, T. Selective laminoplasty after the preoperative diagnosis of the responsible level using spinal cord evoked potentials in elderly patients with cervical spondylotic myelopathy: A preliminary report. J. Spinal. Disord. Tech. 2009, 22, 586-592. [CrossRef] [PubMed]

35. Shiraishi, T. Skip laminectomy-A new treatment for cervical spondylotic myelopathy, preserving bilateral muscular attachments to the spinous processes: A preliminary report. Spine J. 2002, 2, 108-115. [CrossRef]

36. Dahdaleh, N.S.; Wong, A.P.; Smith, Z.A.; Wong, R.H.; Lam, S.K.; Fessler, R.G. Microendoscopic decompression for cervical spondylotic myelopathy. Neurosurg. Focus 2013, 35, E8. [CrossRef]

37. Panjabi, M.M.; White, A.A., 3rd; Johnson, R.M. Cervical spine mechanics as a function of transection of components. J. Biomech. 1975, 8, 327-336. [CrossRef]

38. Stoner, K.E.; Abode-Iyamah, K.O.; Fredericks, D.C.; Viljoen, S.; Howard, M.A.; Grosland, N.M. A comprehensive finite element model of surgical treatment for cervical myelopathy. Clin. Biomech. 2020, 74, 79-86. [CrossRef]

39. Tejapongvorachai, T.; Tanaviriyachai, T.; Daniel Riew, K.; Limthongkul, W.; Tanavalee, C.; Keeratihattayakorn, S.; Buttongkum, D.; Singhatanadgige, W. Curved versus straight-cut hinges for open-door laminoplasty: A finite element and biomechanical study. J. Clin. Neurosci. 2020, 78, 371-375. [CrossRef]

40. Khuyagbaatar, B.; Kim, K.; Purevsuren, T.; Lee, S.H.; Kim, Y.H. Biomechanical Effects on Cervical Spinal Cord and Nerve Root Following Laminoplasty for Ossification of the Posterior Longitudinal Ligament in the Cervical Spine: A Comparison Between Open-Door and Double-Door Laminoplasty Using Finite Element Analysis. J. Biomech. Eng. 2018, 140. [CrossRef]

41. Kubo, S.; Goel, V.K.; Yang, S.J.; Tajima, N. The biomechanical effects of multilevel posterior foraminotomy and foraminotomy with double-door laminoplasty. J. Spinal. Disord. Tech. 2002, 15, 477-485. [CrossRef]

42. Subramaniam, V.; Chamberlain, R.H.; Theodore, N.; Baek, S.; Safavi-Abbasi, S.; Senoğlu, M.; Sonntag, V.K.; Crawford, N.R. Biomechanical effects of laminoplasty versus laminectomy: Stenosis and stability. Spine 2009, 34, E573-E578. [CrossRef] [PubMed]

43. Kode, S.; Gandhi, A.A.; Fredericks, D.C.; Grosland, N.M.; Smucker, J.D. Effect of multilevel open-door laminoplasty and laminectomy on flexibility of the cervical spine: An experimental investigation. Spine 2012, 37, E1165-E1170. [CrossRef] [PubMed]

44. Seichi, A.; Takeshita, K.; Ohishi, I.; Kawaguchi, H.; Akune, T.; Anamizu, Y.; Kitagawa, T.; Nakamura, K. Long-term results of double-door laminoplasty for cervical stenotic myelopathy. Spine 2001, 26, 479-487. [CrossRef]

45. Ratliff, J.K.; Cooper, P.R. Cervical laminoplasty: A critical review. J. Neurosurg. 2003, 98, 230-238. [CrossRef]

46. Mihara, H.; Ohnari, K.; Hachiya, M.; Kondo, S.; Yamada, K. Cervical myelopathy caused by C3-C4 spondylosis in elderly patients: A radiographic analysis of pathogenesis. Spine 2000, 25, 796-800. [CrossRef]

47. Holmes, A.; Wang, C.; Han, Z.H.; Dang, G.T. The range and nature of flexion-extension motion in the cervical spine. Spine 1994, 19, 2505-2510. [CrossRef]

48. Rahmani, M.S.; Terai, H.; Akhgar, J.; Suzuki, A.; Toyoda, H.; Hoshino, M.; Tamai, K.; Ahmadi, S.A.; Hayashi, K.; Takahashi, S.; et al. Anatomical analysis of human ligamentum flavum in the cervical spine: Special consideration to the attachments, coverage, and lateral extent. J. Orthop. Sci. 2017, 22, 994-1000. [CrossRef] [PubMed]

49. Hashiguchi, A.; Kanchiku, T.; Nishida, N.; Taguchi, T. Biomechanical Study of Cervical Posterior Decompression. Asian Spine J. 2018, 12, 391-397. [CrossRef] [PubMed] 